\title{
No Cleavage Enzyme Used
}

National Cancer Institute

\section{Source}

National Cancer Institute. No Cleavage Enzyme Used. NCI Thesaurus. Code C161889.

A technique for processing protein samples for physicochemical analysis where no protease-based reagents were used. 